\begin{tabular}{|l|l|l|l|l|l|}
\hline MUNIBE Antropologia-Arkeologia & $n^{\circ} 71$ & $121-128$ & DONOSTIA & 2020 & ISSN $1132-2217 \cdot$ elSSN $2172-4555$ \\
\hline
\end{tabular}

\title{
Nuevas dataciones de restos humanos en cueva atribuidos a la Edad del Hierro en Cantabria (España)
}

\author{
New ${ }^{14} \mathrm{C}$ datings of human remains attributed \\ to the Iron Age from caves in Cantabria (Spain)
}

PALABRAS CLAVES: cuevas, restos humanos, ofrendas, enterramientos. GAKO-HITZAK: kobazuloak, giza aztarnak, eskaintzak, ehorzketak.

KEY WORDS: caves, human remains, offerings, burials.

\section{Rafael BOLADO DEL CASTILLO(1), Enrique GUTIÉRREZ CUENCA(2), José Ángel HIERRO GÁRATE(3)}

\section{RESUMEN}

Se presentan las dataciones realizadas en el marco del proyecto "El uso de las cuevas durante la Edad del Hierro en Cantabria" sobre restos humanos de las cuevas de La Callejonda, La Graciosa I, La Graciosa II, El Calero II y Lamadrid, atribuidos a ese periodo de la Protohistoria. Aunque diversos investigadores han considerado que se trataba de contextos sepulcrales, los resultados obtenidos en esta investigación permiten descartar esa hipótesis en la mayoría de los casos estudiados.

\section{LABURPENA}

"Kantabrian Burdin Aroan kobazuloek izandako erabilera" proiektuaren baitan egindako datazioak aurkeztu dira Protohistoriako garai horri esleitutako eta kobazulo hauetan topatutako giza aztarnak oinarritzat hartuta: La Callejonda, La Graciosa I, La Graciosa II, El Calero II eta Lamadrid. Ikerlari askoren ustez hilobiekin lotutako testuinguruak diren arren, ikerlanean lortutako emaitzek hipotesi hori baztertzea ahalbidetu dute ikertutako kasu gehienetan.

\section{ABSTRACT}

We present the radiocarbon datings of human remains from the caves of La Callejonda, La Graciosa I, La Graciosa II, El Calero II y Lamadrid made within the project "The use of caves during the Iron Age in Cantabria" and attributed to the Iron Age. Altohugh some researchers have considered these caves to be burial contexts, the results of this investigation allow us to dismiss that theory in most of the cases.

\section{INTRODUCCIÓN}

Las cuevas constituyen un elemento habitual dentro del paisaje de Cantabria y durante toda la Prehistoria, desde el Paleolítico hasta la Edad del Bronce, fueron aprovechadas por los grupos humanos como lugares de hábitat, refugio o espacios funerarios. Resulta lógico suponer que, durante la Edad del Hierro, aunque se imponen nuevos patrones de poblamiento, los espacios subterráneos no fueron abandonados. Esta hipótesis motivó que, desde la década de 1980, parte de los esfuerzos de la investigación en la región se centrasen en la búsqueda de vestigios de esa época en su interior. Los primeros resultados se incluyen ya en el estado de la cuestión realizado por Bohigas (1986-1987), donde se citan siete ejemplos, mientras que la Carta Arqueológica de Cantabria del año 1987 (Muñoz et al., 1987) llegará a recoger 74. Los trabajos posteriores serán más o menos críticos y exhaustivos al analizar este tipo de contextos (Morlote et al., 1996; Peralta, 2003; Cisneros et al., 2008), hasta consolidar un corpus de 129 yacimientos (Smith y Muñoz, 2010). En la actualidad, el Inventario Arqueológico de Cantabria (INVAC) incluye 143 cuevas con restos de la Edad del Hierro.

La interpretación con más peso en la historiografía ha sido la funeraria, ya que se consideraba que los huesos humanos hallados en muchas de esas cuevas eran contemporáneos de los materiales atribuibles a la Edad del Hierro (Smith, 1985; García Alonso y Bohigas, 1995; Morlote et al., 1996; Peralta 2003; Smith y Muñoz, 2010; Torres, 2010; De Luis, 2014). No obstante, de forma paulatina ha ido introduciéndose una nueva hipótesis que nos acerca a un posible uso cultual (Ruiz Cobo y Smith, 2003; Muñoz et al., 2007; Ruiz Cobo et al., 2007; Ruiz Cobo y Muñoz, 2009; Smith y Muñoz, 2010; Torres, 2010; Smith et al., 2013; De Luis, 2014). En algunos trabajos incluso se llegan a distinguir diferentes tipos de ceremonias que podrían haber tenido lugar en esos contextos subterráneos: sacrificios humanos, ritos de paso, banquetes o rituales con fuego (De Luis, 2014).

\footnotetext{
(1) Instituto Internacional de Investigaciones Prehistóricas de Cantabria- IIIPC (Universidad de Cantabria, Gobierno de Cantabria, Santander). rafael.bolado@outlook.es

(2,3) Arqueólogo.
} 


\section{NUEVOS DATOS}

De las 143 cuevas citadas en el INVAC, se han podido revisar los materiales procedentes de $106^{1}$. El resto se halla en paradero desconocido o se trata de piezas que aún permanecen in situ en los yacimientos. El estudio realizado ha permitido confirmar únicamente 22 cuevas con restos, principalmente cerámicos y metálicos, con características morfotipológicas propias de la Edad del Hierro (Bolado, 2020). En 13 de ellas hay restos humanos que han servido en algún momento para considerar que se trataba de contextos funerarios, si bien algunas dataciones realizadas en las últimas décadas habían ido descartando esta posibilidad. Es el caso de la cueva de Cofresnedo (Matienzo), donde los restos de la gatera G-4 y la Sala Pendants fueron datados en la Edad del

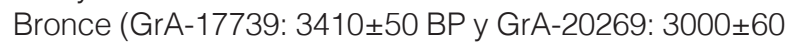
BP) (Ruiz Cobo y Smith, 2003); y de la cueva de Barandas (Matienzo), donde los dos huesos humanos se fechan en época romana temprana (CNA-1119: 1875 \pm 35 BP y CNA-1120: 1910 \pm 25 BP) (Smith et al., 2013: 105).

La datación directa de los restos humanos es una forma objetiva de comprobar si la relación hipotética asumida con los objetos prerromanos, con los que aparentemente se asocian en algunos yacimientos en los que ambos aparecen en superficie, es real o aparente y tiene que ver con distintos usos de la cueva a lo largo del tiempo. Este principio ha sido en el que se ha fundamentado la primera fase del proyecto «El uso de las cuevas durante la Edad del hierro en Cantabria”, financiado por la Consejería de Universidades, Igualdad, Cultura y Deporte del Gobierno de Cantabria, desarrollada en 2019. En este marco se han realizado dataciones por ${ }^{14} \mathrm{C}$ AMS en el Centro Nacional de Aceleradores de la Universidad de Sevilla sobre huesos humanos procedentes de cinco cuevas: Callejonda, Graciosa I, Graciosa II, Calero II y Lamadrid (Fig. 1). La elección de las mismas se ha basado en dos criterios:

1. En todas ellas se han documentado materiales adscribibles a la Segunda Edad del Hierro y restos óseos humanos.

2. Las cinco cavidades, junto a las ya citadas Cofresnedo, Barandas y la cueva del Aspio (Serna. et al., 1994; Bolado y Cubas, 2016; Bolado et al. 2020; Bolado 2020: 312-337), son los ejemplos más emblemáticos sobre los que se asientan las hipótesis funerarias y rituales, siendo en este último sentido de especial interés la cueva de la Graciosa II, cuyos cráneos han sido relacionados con la práctica de las cabezas cortadas (Fernández Acebo et al., 2004: 82; Torres, 2011: 402; De Luis, 2014: 146).

La cueva de Callejonda se encuentra localizada a 267 m de altitud sobre la ladera sur del Monte Redon- do (Tarriba, San Felices de Buelna). La boca, con una orientación este, posee unos $3 \mathrm{~m}$ de anchura por 2,5/3 $\mathrm{m}$ de altura. Desde ella se accede a una galería baja y ancha de $10 \mathrm{~m}$ de longitud por la que se llega hasta una sala en donde se hallaron los distintos restos arqueológicos. Desde este punto continúa su desarrollo durante más de 40 m a través de pequeñas galerías y gateras. Su exploración y prospección fue llevada a cabo por el CAEAP en 1987 y años posteriores. Según recogen Morlote et al. (1996: 226) los materiales se ubicaban en dos salitas contiguas. En la sala interna se documentaron varios fragmentos cerámicos de orzas con impregnaciones plásticas, una cuenta cilíndrica de bronce y un fémur humano con marcas de fuego. En la sala aledaña, por su parte, se recogieron restos de una olla de perfil en "S", un galbo bruñido, fragmentos cerámicos con impregnaciones plásticas y decoraciones de cordones, dos restos de cráneo con evidencias de haber sido quemados y varias piezas de bronce. Entre estas últimas es posible identificar dos pendientes amorcillados, cuatro chapas de bronce y una placa decorativa para correaje o cinturón de tendencia rectangular (Morlote et al., 1996; Bolado, 2020) que puede ser incluida en el tipo C1B1 de broches de Lorrio (1997: 178-188), el cual fecha entre finales del siglo IV a.C. y el siglo III a.C., aunque en Cantabria puede documentarse hasta momentos cercanos al cambio de era. La relación de estos materiales de la Segunda Edad del Hierro con los restos humanos fue lo que llevó a plantear la hipótesis de que nos encontrábamos con hasta dos enterramientos distintos (Molorte et al., 1996: 226; Ruiz Cobo, 1996a: 122; Peralta, 2003: 68; Smith y Muñoz, 2010: 690), por lo que se procedió, con el fin de verificarla, a la datación de un fragmento de diáfisis de fémur, de lateralidad no determinada, que proporcionó un resultado de 4723 227 BP (CNA-5210), que ofrece un intervalo al 95,4\% de probabilidad de 3629-3377 cal BC²; lo que situaría el uso sepulcral, en el Neolítico final, sin relación con los materiales de la Edad del Hierro (Fig.2, 3 y 4A).

Las cuevas de La Graciosa I y II se localizan a 130 $\mathrm{m}$ de altitud, al sur de Pico Castillo (Medio Cudeyo), disponiéndose una prácticamente al lado de la otra. La Graciosa I es una cavidad fósil con una boca de 1,5 $\mathrm{m}$ de altura por $2 \mathrm{~m}$ de anchura que da acceso a un vestíbulo de $7 \mathrm{~m}$ de longitud por $2 \mathrm{~m}$ de anchura tras el cual nos encontramos con una amplia sala de $5 \mathrm{~m} \times 5 \mathrm{~m}$; esta se prolonga a partir de una galería recta que finaliza en un pozo de $7 \mathrm{~m}$ de profundidad. El yacimiento, descubierto en la década de los cincuenta del siglo XX por los Camineros de la antigua Diputación de Santander y explorado nuevamente en la década de los ochenta por el CAEAP, se localiza tanto en el vestíbulo como en la salita interior. Del vestíbulo proceden algunos fragmentos de cerámica medieval mientras que en el interior se han documentado

\footnotetext{
1 Este trabajo ha sido llevado a cabo por uno de los firmantes de ese trabajo (RBC) con motivo de su tesis doctoral (Bolado, 2020).

2 Todas las dataciones de radiocarbono se han calibrado con el programa OxCal ver. 4.3.2 empleando la curva IntCal 20 (Reimer et al., 2020).
} 


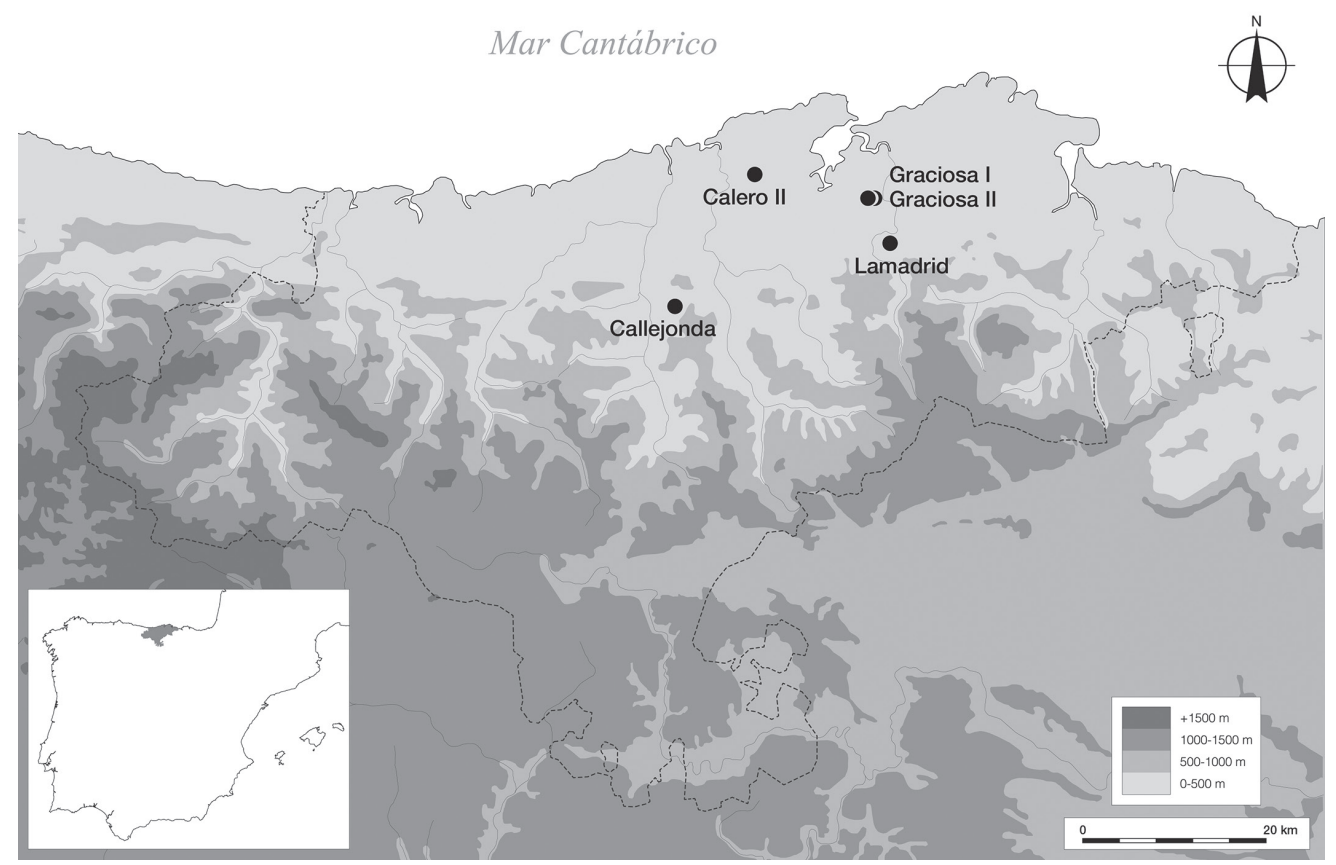

Fig.1. Localización de las cuevas. / Location of caves.

otros de cerámica fabricada a mano y a torno, fauna y restos humanos que se han relacionado con una inhumación colectiva formada por ocho individuos (Morlote et al., 1996: 236; Valle y Serna, 2003; Fernández Acebo et al., 2004). La Graciosa II, reconocida en 1982 por miembros del CAEAP, es una pequeña cavidad con una boca de $1 \mathrm{~m}$ de altura y $3 \mathrm{~m}$ de anchura desde la que se accede a un vestíbulo de $6 \mathrm{~m}$ de longitud y $3 \mathrm{~m}$ de ancho. Al fondo del mismo, en la pared derecha, existe una galería muy estrecha de $3 \mathrm{~m}$ de longitud y $60 \mathrm{~cm}$ de anchura, donde se recuperaron restos de ocho cráneos humanos. El yacimiento parece extenderse por toda la cavidad proporcionando más restos humanos, fauna, fragmentos de cerámica prehistórica, cerámica medieval y restos de talla lítica (Morlote et al., 1996: 236-238; Valle y Serna, 2003; Fernández Acebo et al., 2004).

La atribución a la Edad del Hierro de ambas cavidades se basa en la identificación de algunos fragmentos de ollas de perfil en "S"3 y cerámica tardoceltibérica (Bohigas et al., 1984: 142; Rasines 1986-1988; Morlote et al., 1996: 236-238; Valle y Serna, 2003: 386-387), aunque actualmente no se conservan en los fondos del Museo de Prehistoria y Arqueología de Cantabria. A partir de ella, se ha manejado la misma cronología para los restos humanos, destacándose principalmente los ocho cráneos de Graciosa II, los cuales han sido interpretados como restos de sacrificios rituales o del culto de las cabezas cortadas (Fernández Acebo et al., 2004: 82; De Luis, 2014: 146; Torres, 2011: 402). Sin embargo, las tres dataciones realizadas nos alejan de este periodo y ponen en duda la interpretación planteada. Un fragmento de hueso temporal del cráneo de La Graciosa I proporcionó un resultado de 4522 $\pm 27 \mathrm{BP}$ (CNA-5212), que ofrece un intervalo al 95,4\% de probabilidad de 3360-3102 cal BC (Fig.2, 3 y 4B). Por su parte, dos de los cráneos de La Graciosa II, de los cuales se extrajeron muestras del hueso occipital, arrojaron los resultados 4202 \pm 27 BP (CNA5214), con un intervalo de 2895-2675 cal BC, y $4194 \pm 27$ BP (CNA-5213), con uno de 2891-2671 cal BC (Fig.2, 3, $4 C$ y D). Los restos humanos corresponden, por tanto, a sepulturas realizadas entre el Neolítico final y el Calcolítico lo que no permite, por el momento, sostener la hipótesis de un uso funerario de estas cuevas durante la Edad del Hierro ni, obviamente, seguir manteniendo la existencia de un ritual de cabezas cortadas.

La cueva de El Calero II se alza a 45 m de altitud sobre la falda oeste de una pequeña loma que mira a los barrios de la Lastra y Soito (Puente Arce, Piélagos), situados en la margen occidental del río Pas. Se trata de una pequeña cavidad fósil de $220 \mathrm{~m}$ de desarrollo con una boca de apenas un metro de altura por un metro de anchura. Desde esta se accede a un vestíbulo cuyo fondo está cerrado por un muro de piedras trabadas con arcilla. Tras él se continúa por una galería descendente y recta que gira a la derecha hasta llevarnos a otra sala en cuyo fondo se abre una nueva galería ascendente que se dirige hasta una boca colmatada. El material arqueológico se halla disperso por toda la cavidad (Crespo et al., 2007). La cueva fue descubierta en los años noventa del siglo XX por miembros del CAEP y GEIS C/R (Carba-

\footnotetext{
3 Las ollas de perfil en "S" fueron consideradas durante un tiempo como propias de la Edad del Hierro en Cantabria. Sin embargo, investigaciones más recientes han acreditado la cronología tardoantigua y altomedieval de muchas de esas vasijas (Gutiérrez y Hierro, 2016).
} 
Ilo/Raba), siendo estudiada en 1995 por E. Muñoz y J.M. Morlote (Muñoz y Morlote, 2000). Entre los restos materiales descubiertos en superficie, los cuales se hayan mayoritariamente aún en la cueva, se identificaron industria lítica, placas de bronce, carbones, restos humanos y diversos fragmentos cerámicos. Varios restos óseos y fragmentos cerámicos fueron fechados. Por ${ }^{14} \mathrm{C}$ AMS se dataron uno de los dos individuos infantiles localizados en una oquedad estalagmítica del interior (AA-29651, $760 \pm 55 \mathrm{BP})$, una de las pinturas negras del gran panel (AA-20046: 25185 $\pm 450 \mathrm{BP}$ ), una de las marcas negras de la sala central (AA-20047: 1227士93 BP) y un carbón procedente de una acumulación de la gran sala (AA29652, 1265 \pm 60 BP). A través de termoluminiscencia se fecharon un fragmento cerámico de un recodo interior asociado a restos humanos (MAD-668: 5482 $\pm 422 \mathrm{BP}$ ); una pieza perteneciente a una olla estriada (MAD-672: $1129 \pm 90$ BP); un fragmento de olla de perfil en "S", recuperado al inicio de la galería de las pinturas (MAD-672: $1904 \pm 148$ BP), y un gran vaso completo, bruñido y liso, con pie anular indicado, descubierto en la galería que conduce a la gran sala (MAD-671: 2285 \pm 204 BP). Este aparece asociado a carbones vegetales, al igual que los restos de otras vasijas descubiertas en la cueva las cuales, ocasionalmente, cuentan en su entorno con placas finas de bronce (Muñoz y Morlote, 2000; Muñoz et al., 2007). La vinculación de la cavidad con la Edad del Hierro proviene de las dataciones del gran vaso y la olla de perfil en "S", las cuales permiten situar las vasijas entre el 694 a.C. y el 122 d.C. y entre el 201 a.C. y el 391 d.C., respectivamente. Cerca del gran vaso, con una relación espacial directa, se identificaron restos humanos que pudieran sugerir también una relación cronológica y, por tanto, que nos encontrásemos ante un enterramiento de la Edad del Hierro. Ante esta posibilidad se seleccionaron un molar y un fragmento de diáfisis de tibia izquierda para su datación. El primero de ellos proporcionó una fecha de 3419 \pm 27 BP (CNA-5209), con un intervalo 18711623 cal BC al 95,4\% de probabilidad, mientras que el segundo se dató en 3442 \pm 27 BP (CNA-5208), con un intervalo 1879-1638 cal BC al 95,4\% de probabilidad (Fig.2, 3, 4E y F). Los restos humanos datados corresponden, por lo tanto, a sepulturas del Bronce Antiguo, disociándose así cronológicamente de las vasijas prerromanas y eliminando, de momento, la posibilidad del aprovechamiento del Calero II como espacio funerario durante la Edad del Hierro.
La cueva de Lamadrid se localiza en el municipio de Riotuerto, a unos $172 \mathrm{~m}$ de altitud sobre una pequeña loma que se alza al este de la Mies del Cementerio y Casa Labín. Su boca, descendente entre grandes bloques, hacia la derecha lleva a una sala donde se recogieron distintos restos que fueron relacionados con un posible depósito sepulcral. Más adelante, tras superar un escalón de un metro, se llega a una pronunciada rampa que sigue descendiendo en galería hasta el fondo, pasando antes de llegar al final por una nueva galería que toma dirección oeste para continuar paralela a la principal hasta casi enlazar con el posible enterramiento. La cavidad fue descubierta a finales de los años sesenta o comienzos de los setenta por un grupo francés de espeleología. Estos informaron del hallazgo al Museo de Prehistoria y Arqueología de Cantabria desde donde se procedió a su exploración, recogiéndose así varios fragmentos cerámicos relacionados con ollas de perfil en "S". Años después fue estudiada por el CAEAP quienes, junto a "materiales acumulados en montones por los investigadores anteriores", reconocieron distintos restos en superficie distribuidos en seis zonas (Pintó, 1980-1981: 30; Morlote et al., 1996: 242-245; Pintó et al., 1996: 29-30). Mayoritariamente se trata de fragmentos cerámicos pertenecientes a orzas con impregnaciones plásticas, fragmentos de cerámicas prehistóricas fabricadas a mano, fauna y restos humanos. El estudio de los materiales depositados en el Museo de Prehistoria y Arqueología de Cantabria, ante la falta de cualquier tipo de información relativa a su lugar de hallazgo, imposibilita conocer de dónde procede cada pieza y sus relaciones espaciales. No obstante ha sido posible individualizar un conjunto de bordes cuyas características morfotipológicas los relacionan con las producciones de la Segunda Edad del Hierro (Bolado, 2020). La presencia de restos humanos supuestamente asociados a estos materiales cerámicos había servido para proponer su uso funerario durante ese periodo (Morlote et al., 1996: 245) por lo que se procedió a tratar de verificar esta hipótesis mediante la datación de un húmero izquierdo. Este proporcionó un resultado de 2058 \pm 27 BP (CNA-5211), ofreciendo un intervalo al 95,4\% de probabilidad que lo sitúa entre el 156 cal BC y el 16 cal AD (Fig.2, 3 y 4G). Esta datación permite por tanto plantear el uso sepulcral de la cueva durante la Segunda Edad del Hierro, aunque sería necesario llevar a cabo una intervención arqueológica más extensa para conocer sus características.

\begin{tabular}{|c|c|c|c|c|}
\hline Yacimiento & Muestra & Ref. Lab. & Datación BP & Datación cal $2 \sigma(95,4 \%)$ \\
\hline Callejonda & h. humano & CNA-5210 & $4723 \pm 27$ & 3629-3377 cal BC \\
\hline Graciosa I & h. humano & CNA-5212 & $4522 \pm 27$ & $3360-3102 \mathrm{cal} \mathrm{BC}$ \\
\hline Graciosa II & h. humano & CNA-5214 & $4202 \pm 27$ & $2895-2675$ cal BC \\
\hline Graciosa II & h. humano & CNA-5213 & $4194 \pm 27$ & 2891-2671 cal BC \\
\hline Calero II & h. humano & CNA-5208 & $3442 \pm 27$ & 1879-1638 cal BC \\
\hline Calero II & h. humano & CAN-5209 & $3419 \pm 27$ & $1871-1623 \mathrm{cal} \mathrm{BC}$ \\
\hline Lamadrid & h. humano & CNA-5211 & $2058 \pm 27$ & 156 cal BC-16 cal AD \\
\hline
\end{tabular}




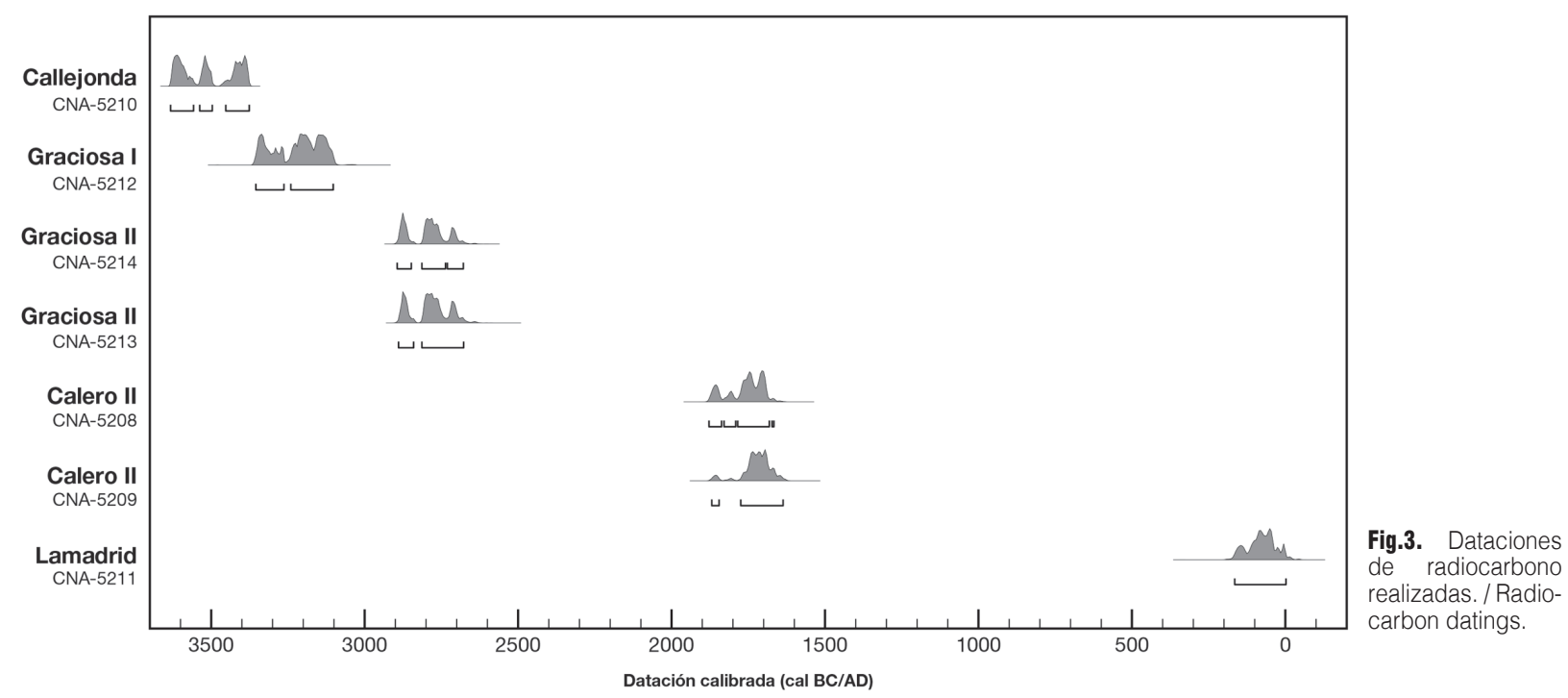

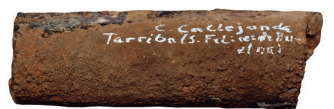

A

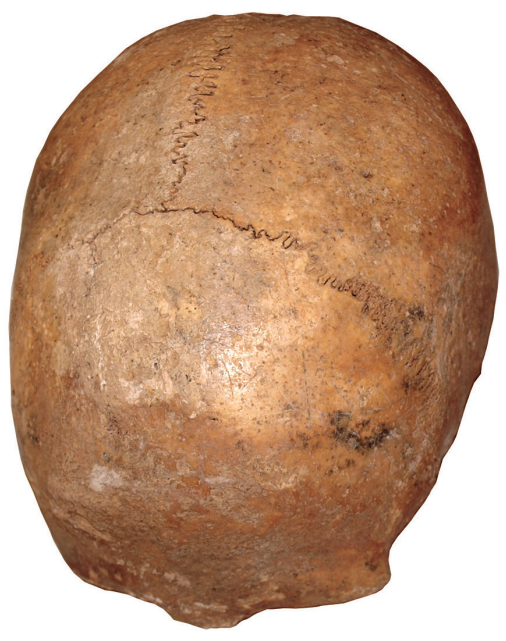

C

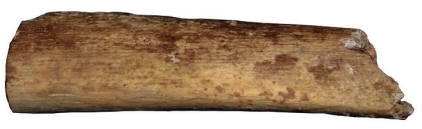

E

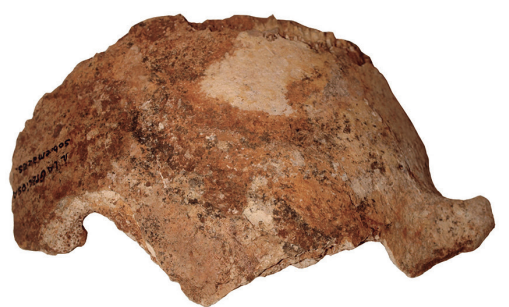

B

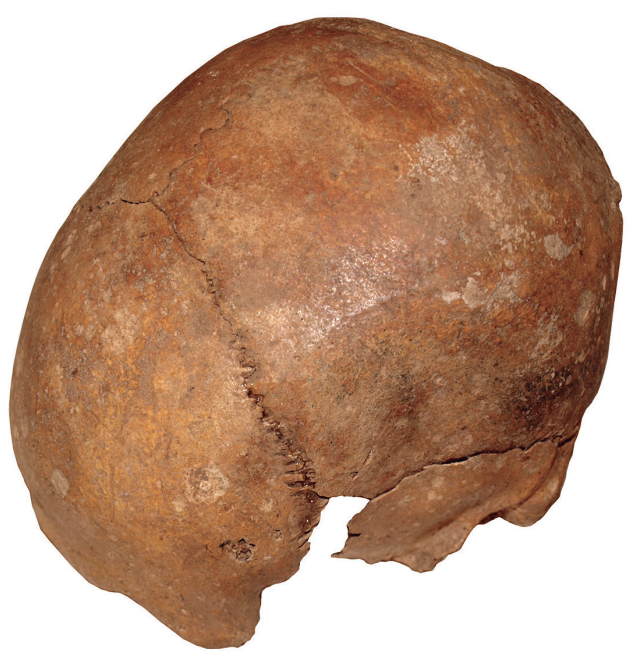

D

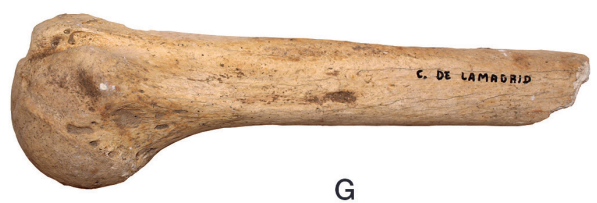

G
Fig.4. Huesos humanos datados: A) La Callejonda, CNA-5210; B) La Graciosa I, CNA-5212; C) La Graciosa II, CNA-5214; D) La Graciosa II, CNA-5213; E) Calero II, CNA-5209; F) Calero II, CNA5208 y G) Lamadrid, CNA-5211. I Human bones dated: A) La Callejonda, CNA-5210; B) La Graciosa I, CNA-5212; C) La Graciosa II, CNA-5214; D) La Graciosa II, CNA-5213; E) Calero II. CNA5209; F) Calero II, CNA-5208 y G) Lamadrid, CNA-5211. 


\section{DISCUSIÓN}

Los resultados de las dataciones realizadas hasta la fecha sobre restos humanos en algunas cuevas de Cantabria que conservan materiales de la Edad del Hierro nos permiten desestimar, con carácter general, la hipótesis que considera estos espacios como lugares de uso funerario habitual. La única excepción, por el momento, es la cueva de Lamadrid, en la que se centrará la segunda parte del proyecto. Como hemos visto, en la mayoría de los casos se trata de inhumaciones realizadas durante el Neolítico final, el Calcolítico y los inicios de la Edad del Bronce, algo que, por otro lado, encaja con las costumbres funerarias identificadas en la región cantábrica para el periodo comprendido entre la segunda mitad del III milenio cal BC y la segunda mitad del II milenio cal BC; una larga etapa en la que se generalizan las cuevas sepulcrales (Ontañón y Armendáriz, 2005). Algo similar ya se había constatado para algunas de las cuevas para las que se proponía un uso sepulcral en época visigoda, en las que, de nuevo, las asociaciones de restos humanos y materiales arqueológicos eran más aparentes que reales y los primeros remitían, mayoritariamente, a distintos momentos de la Prehistoria Reciente (Gutiérrez y Hierro, 2010-2012).

En el caso que nos ocupa, la propia conservación de los huesos es uno de los factores que sirven para apoyar la cronología apuntada por las dataciones. Estos aparecen de forma frecuente completos o mostrando un gran desarrollo, sin marcas sobre su superficie que evidencien que fueron afectados o sometidos a la acción del fuego. Esta práctica distaría de la establecida con carácter general en la Edad del Hierro peninsular y por la cual el difunto era cremado y sus huesos machacados, seleccionándose solamente una parte para ser depositada junto con el ajuar (Lorrio, 1997: 345-348; Torres 2011: 533-538). No obstante, debemos señalar que sí que se conocen restos humanos fechados en la Primera Edad del Hierro en unas pocas cuevas, como la de Fuentenegroso (Asturias) (Barroso et al., 2007) o el complejo de Ojo Guareña (Burgos) (Ruiz Vélez, 2009). No ocurre lo mismo en otras zonas del continente, donde el uso sepulcral de las cuevas a lo largo de la Edad del Hierro cuenta con buenos ejemplos, como pueden ser los casos franceses del Aven de Plérimond (Boyer et al., 2006) o la Grotte des Palabres (Crubézy et al., 2000) para la primera Edad del Hierro; o de la Grotte Rochefort (Colleter et al., 2007), fechada ya hacia el cambio de era.

La presencia de abundante sedimento carbonoso en la cueva del Aspio (Ruesga) la convirtió en uno de los principales ejemplos de cavidades con restos de presuntas incineraciones (Serna et al., 1994: 391-394; Peralta, 2003: 109; Ruiz et al., 2007: 91). Sin embargo, la actuación arqueológica llevada a cabo en ella entre 2013 y 2017, durante la que se abordó la flotación de todo el sedimento extraído y un triaje detallado, permitió descartar completamente la presencia de restos huma- nos (Bolado y Cubas, 2016; Bolado et al., 2020). Las vasijas, armas, objetos de adorno personal, piezas de telar, fauna y granos de cereal dejaban así de ser vistos como un ajuar funerario y pasaban a considerarse posibles ofrendas de una práctica cultual que, con los mismos elementos y cronología, se repite en la cercana cueva de Cofresnedo (Ruiz y Smith, 2003). Esta misma función se puede proponer para gran parte de los depósitos en cueva de la Edad del Hierro en Cantabria. Algo que, por otra parte, está en sintonía con lo que sucede en otras zonas de la península lbérica (Alfayé, 2009; Llanos et al., 2011) y que, presumiblemente, se explica por una concepción de los espacios subterráneos como la morada o la vía de comunicación con los dioses, convirtiéndose en un elemento fundamental de la cosmogonía de los pueblos prerromanos.

Finalmente, hay que señalar que, además de suponer un punto de partida para el estudio en profundidad de una cueva con uso sepulcral seguro durante la Edad del Hierro y descartar ese carácter funerario en otras para las que se venía proponiendo, este trabajo aporta una batería de dataciones prehistóricas que vienen a completar las ya conocidas en otras cuevas de Cantabria y que pueden constituir los fundamentos para uno o varios trabajos centrados en esos periodos históricos. Trabajos que, huelga decirlo, escapan a los objetivos del proyecto que está detrás de éste, centrados en la Edad del Hierro.

\section{BIBLIOGRAFÍA}

Alfayé, S., 2009. Santuario y rituales en la Hispania Céltica. BAR International Series 1963.

Barroso Bermejo, R., Camino Mayor, J., Bueno Ramírez, P., de Balbín Behrmann, R., 2007. Fuentenegroso. Un enterramiento del I milenio a.C. en la Sierra de Cuera (Asturias). Consejería de Cultura, Comunicación Social y Turismo. Gobierno de Asturias.

Bohigas Roldán, R., 1986-1987. La Edad del Hierro en Cantabria. Estado de la cuestión. Zephyrus XXXIX-XL, 119-138.

Bohigas Roldán, R., Muñoz Fernández, E., Peñil Mínguez, J., 1984. Las ocupaciones recientes en las cuevas. Boletín Cántabro de Espeleología 4, 140-159.

Bolado del Castillo, R., Cubas, M., 2016. La cueva del Aspio (Ruesga). Nuevas intervenciones arqueológicas. En: Cantabria, nuevas evidencias arqueológicas, 91-118. ADIC-Editorial Los Cántabros, Santander.

Bolado del Castillo, R., 2020. La cultura material de la Edad del Hierro en Cantabria. Tesis doctoral. Universidad de Cantabria.

Bolado del Castillo, R., López Bultó, O., Cubas, M., 2020. Wooden technology during the Iron Age: The Aspio Cave (Ruesga, Cantabria, Spain). Oxford Journal of Archaeology 39(1), 89-106.

Boyer, R., Dedet, B., Marchand, G., 2006. L'aven sépulcral de Plerimond à Aups, Var (Vle s. av. J.-C.). Gallia 63, 171-209.

Cisneros Cunchillos, M., Marco Simón, F., Pina Polo, F., Ramírez Sádaba, J.L., 2008. La situación de los pueblos cántabros antes de la conquista romana. In: Aja, J.R., Cisneros, M., Ramírez, J.L. (Coords), Los cántabros en la antigüedad. La Historia frente al Mito, 49-99, Universidad de Cantabria. 
Colleter, R., Aubien, G., Cherel, A. F., Hinguant, S., Peuziat, J., Sellami, F., 2007. Un ensemble funéraire de la transition âge du fer-Antiquité en contexte karstique: la grotte Rochefort à Saint-Pierre-sur-Erve (Mayenne). Revue archéologique de I'Ouest 24, 89-109.

Crespo Lastra, V., Muñoz Fernández, E., Gómez Arozamena, J., Bermejo Castrillo, A. y González Luque, C., 2007. Catálogo de Cavidades del municipio de Piélagos. Actuaciones Espeleológicas 1986-2003. In: Crespo, V. (Coord.), Catálogo de Cavidades del municipio de Piélagos. Actuaciones espeleológicas 1986-2003, 163-215. Ayuntamiento de Piélagos, Grupo de Espeleología e Investigaciones Subterráneas "Carballo/Raba".

Crubézy, E., Giraud, J.P., Rouzaud, F., Salgues, T., Coqueugnot, H., Le Guillou, J.L., Murail, P., Soulier, M., Du Fayet de la Tour, A., 2000. Un ensemble funéraire exceptionnel du premier Âge du Fer en Quercy: la grotte des Palabres (Boussac, Lot). In: Dedet, B., Gruat, P., Marchand, G., Py, M., Schwaller, M. (Eds.), Archéologie de la Mort, Archéologie de la Tombe au Premier Âge du Fer, Lattes, 123-129.

De Luis Mariño, S., 2014. Aproximación al uso ritual de las cuevas en la Edad del Hierro: el caso del Cantábrico Centro-Oriental (Península Ibérica). Munibe Antropologia-Arkeologia $65,137-156$.

Fernández Acebo, V., Serna Gancedo, M.L., Muñoz Fernández, E., 2004. El macizo de Peña Cabarga (Cantabira): recorrido por el tiempo y el patrimonio. ACANTO.

García Alonso, F., Bohigas Roldán, R., 1995. El Valle de Soba. Arqueología y Etnografía. Santander, Tres, D.L.

Gutiérrez Cuenca, E., Hierro Gárate, J.A., 2010-2012. Nuevas evidencias sobre el uso de las cuevas de Cantabria durante la Tardoantigüedad y la Alta Edad Media. Primeros resultados del Proyecto Mauranus. Sautuola XVI-XVII, 263-280.

Gutiérrez Cuenca, E., Hierro Gárate, J.A., 2016. La cerámica en Cantabria entre la Antigüedad Tardía y la Alta Edad Media (siglos V-X). In: Vigil-Escalera, A., Quirós, J. A. (Dir.), La cerámica de la Alta Edad Media en el cuadrante noroeste de la Península Ibérica (siglos V-X). Sistemas de producción, mecanismos de distribución y patrones de consumo, 172-191. Documentos de Arqueología Medieval 9. Vitoria.

Llanos Ortiz de Landaluce, A., Urrutia Agorreta, M.N., 2011. Intervenciones arqueológicas en el castro de Urisolo, y las cavidades de Urisolo y Goba de Unda (Letona, Álava). Estudios de Arqueología Alavesa 27, 79-134.

Lorrio, A.J., 1997. Los Celtíberos. Universidad Complutense de Madrid y Universidad de Alicante.

Morlote, J.M., Muñoz, E., Serna, A., Valle, Mª A., 1996. Las cuevas sepulcrales de la Edad del Hierro en Cantabria. La Arqueología de los Cántabros. Actas de la Primera Reunión sobre la Edad del Hierro en Cantabria, Fundación Marcelino Botín, 195-279.

Muñoz Fernández, E., Gómez Arozamena, J., Morlote Expósito, J.M., Crespo Lastra, C., Bermejo Castrillo, A., San Miguel Llamosas, C., González Luque, C., 2007. La arqueología de las cuevas del municipio de Piélagos. In: Crespo, V. (Coord.), Catálogo de Cavidades del municipio de Piélagos. Actuaciones espeleológicas 1986-2003, 32-63. Ayuntamiento de Piélagos, Grupo de Espeleología e Investigaciones Subterráneas "Carballo/Raba".

Muñoz Fernández, E., Morlote Expósito, J.M., 2000. Documentación arqueológica de la cueva del Calero II y la sima del Portillo del Arenal, en Piélagos. In: Ontañón, R. (Coord.), Ac- tuaciones Arqueológicas en Cantabria. 1984-1999. Consejería de Cultura, Gobierno de Cantabria, 263-266.

Muñoz Fernández, E., San Miguel Llamosa, C., C.A.E.A.P., 1987. Carta Arqueológica de Cantabria. Ediciones Tantín.

Ontañón, R., Armendáriz, A., 2005. Cuevas y megalitos: los contextos sepulcrales colectivos en la Prehistoria reciente cantábrica. Munibe Antropologia-Arkeologia 57, 275-286.

Reimer, P., Austin, W., Bard, E., Bayliss, A., Blackwell, P., Bronk Ramsey, C., Butzin, M., Cheng, H., Edwards, R., Friedrich, M., Grootes, P., Guilderson, T., Hajdas, I., Heaton, T., Hogg, A., Hughen, K., Kromer, B., Manning, S., Muscheler, R., Palmer, J., Pearson, C., Van der Plicht, J., Reimer, R., Richards, D., Scott, E., Southon, J., Turney, C., Wacket, L., Adolphi, F., Büntgen, U., Capano, M., Fahmi, S., Fogtmann-Schulz, A., Friedrich, R., Köhler, P., Kudsk, S., Miyake, F., Olsen, J., Reining, F., Sakamoto, M., Sookdeo, A., Talamo, S., 2020. The IntCal20 Northern Hemisphere radiocarbon age calibration curve $(0-55 \mathrm{cal}$ kBP). Radiocarbon 62.

Peralta Labrador, E., 2003. Los Cántabros antes de Roma. Real Academia de la Historia, Madrid

Peralta Labrador, E., Ocejo Herrero, A., 1996. El poblamiento de la Edad del Hierro en el sector central del cantábrico. La Arqueología de los Cántabros. Actas de la Primera Reunión sobre la Edad del Hierro en Cantabria, 21-63.Fundación Marcelino Botín.

Pintó Garrido, A., 1980-1981. Cueva prehistóricas en el municipio de Riotuerto. Asociación Cántabra para la Defensa del Patrimonio Subterráneo. Memorias n², 30.

Pintó Garrido, A., Palacios, T., Canales, F., 1996. Trabajos en el Karst de Riotuerto. Boletín Cántabro de Espeleología 12, 5-50.

Rasines, P., 1986-1988. Algunos hallazgos antropológicos en las cuevas de Cantabria. Sautuola V, 19-46.

Ruiz Cobo, J., 1996. La cerámica de la Edad del Hierro en el sector central de la Cornisa Cantábrica. La Arqueología de los Cántabros. Actas de la Primera Reunión sobre la Edad del Hierro en Cantabria, 115-147. Fundación Marcelino Botín.

Ruiz Cobo, J., Muñoz Fernández, E., 2009. La Prehistoria del Bajo Asón. Registro arqueológico e interpretación cultural (Cantabria, España). BAR International Series 1936.

Ruiz Cobo, J., Smith, P., 2003. La cueva de Cofresnedo en el valle de Matienzo. Actuaciones Arqueológicas 1996-2001. Monografías Arqueológicas de Cantabria. Gobierno de Cantabria.

Ruiz Cobo, J., Muñoz Fernández, E., García Gómez, P., Crespo, V., Moñino Sáez, M., Smith, P., 2007. Paisaje y arqueología en el Alto Asón (Cantabria, España): resultados del proyecto de prospección arqueológica del Alto Asón. Archaeopress, Oxford. BAR International Series, 1614.

Ruiz Vélez, I., 2009. La cueva de Ojo Guareña (Burgos): El "príncipe" que se perdió y murió en ella. Sautuola XV, 261-274.

Serna, A., Malpelo, B., Muñoz, E., Bohigas, R., Smith, P., García, M., 1994. La cueva del Aspio (Ruesga, Cantabria): avance al estudio del yacimiento. En: Lasheras, J.A. (Ed.) Homenaje al Dr. Joaquín González Echegaray, 369-396. Monografías Centro de Investigación y Museo de Altamira 17.

Smith, P., 1985. Restos de la Edad del Hierro en Matienzo. Altamira. Revista del Centro de Estudios Montañeses XL, 45-66.

Smith, P., Muñoz Fernández, E., 2010. Las cuevas de la Edad del Hierro en Cantabria. In: Serna, M.L., Martínez, A., Fernández, V. (Coords.) Castros y castra en Cantabria. Fortificacio- 
nes desde los orígenes de la Edad del Hierro a las guerras con Roma, 676-693. ACANTO.

Smith, P., Ruiz Cobo, J., Corrín, J., 2013. La cueva de Las Barandas (Matienzo, Cantabria): depósito y muerte. Sautuola XVIII, 101-114.

Torres Martínez, J.F., 2010. Arqueología de la religión protohistórica en los pueblos del norte: el caso de los cántabros. In: Serna, M.L., Martínez, A., Fernández, V. (Coords.) Castros y castra en Cantabria. Fortificaciones desde los orígenes de la Edad del Hierro a las guerras con Roma, 694-749. ACANTO.

Torres Martínez, J.F., 2011. El cantábrico en la Edad del Hierro. Real Academia de la Historia.

Valle Gómez, Mª A., Serna Gancedo, M.L., 2003. El Castro de Castilnegro y otros asentamientos de la Edad del Hierro en el entorno de la Bahía de Santander. In: Fernández Ibáñez, C., Ruiz Cobo, J. (Eds.) La Arqueología de la Bahía de Santander, 351-390. Fundación Marcelino Botín, Santander. 